\title{
MANAJEMEN STRATEGIK PEMASARAN PENDIDIKAN BERBASIS MEDIA SOSIAL DI MADRASAH ALIYAH YAYASAN PONDOK PESANTREN BABAKAN JAMANIS PARIGI PANGANDARAN
}

\author{
Neneng Nurmalasari dan Imas Masitoh \\ STITNU Al Farabi Pangandaran \\ Email: nurmalasarineneng0@gmail.com danimasmasitohtigasatu@gmail.com
}

\begin{abstract}
Abstrak
Penelitian ini menjelaskan gambaran tentang penggunaan media sosial sebagai manajemen strategi pemasaran di Madrasah Aliyah Yayasan Pondok Pesantren Babakan Jamanis. Manfaat media sosial sebagai alat pemasaran dalam dunia pendidikan pada era revolusi industri 4.0 ini menjadi pilihan yang sangat tepat karena semakin mudah diakses oleh berbagai kalangan. Penelitian ini merupakan penelitian kualitatif dengan metode pengumpulan data melalui observasi, wawancara mendalam dan dokumentasi. Hasil penelitian menunjukan bahwa manajemen strategi pemasaran pendidikan berbasis media sosial yang digunakan yaitu: Facebook, Instagram, dan Youtube dengan mengidentifikasi terlebih dulu di lingkungan masyarakat yang kemudian menjadi strategi pemasaran pendidikan dengan menonjolkan prestasi lembaga tersebut. Pengelolaan pendidikan yang bersifat swasta, didukung dengan stakeholders dan fasilitas yang memadai telah memberikan ciri khas dan kekuatan pada manajemen strategi pemasaran pendidikan di Madrasah Aliyah Yayasan Pondok Pesantren Babakan Jamanis.
\end{abstract}

Kata Kunci : Manajemen, Strategi,Pemasaran Pendidikan, Media Sosial

\begin{abstract}
This study describes an overview of the use of social media as a management marketing strategy at Madrasah Aliyah Yayasan Pondok Pesantren Babakan Jamanis. The benefits of social media as a marketing tool in the world of education in the era of the 4.0 industrial revolution are the right choice because it is increasingly accessible to various groups. This research is qualitative research with data collection methods through observation, in-depth interviews, and documentation. The results show that the social media-based educational marketing strategy management is used, namely: Facebook, Instagram, and Youtube by first identifying in the community which then becomes an educational marketing strategy by highlighting the achievements of these institutions. The management of private education, supported by stakeholders and adequate facilities has provided a distinctive feature and strength in the management of educational marketing strategies at Madrasah Aliyah Yayasan Pondok Pesantren Babakan Jamanis.
\end{abstract}

Keywords : Management, Strategy, Marketing Education, Social Media 


\section{PENDAHULUAN}

Memasuki zaman globalisasi, zaman dimana kompetitif sudah masuk disemua lini kehidupan. Konsep ini menciptakan paradigma borderless wold, yaitu dunia yang tidak mengenal batas-batas teritorial kedaulatan sebuah negara/bangsa. Dampaknya turut menciptakan persaingan yang semakin tinggi pada semua aspek kehidupan masyarakat termasuk didalamnya pendidikan. Apalagi di era sekarang persaingan diranah pendidikan sudah menyentuh titik dimana persaingan berbasis media sosial yang sangat mudah di akses masyarakat.

Hidup di zaman kompetitif seperti ini, sangat sulit jika kita tidak memiliki kemampuan mengubah diri dengan cepat dan mampu berkembang seiring dengan berbagai tuntutan stakeholder. Kondisi ini berlaku hampir pada seluruh organisasi yang bersifat profit maupun non profit. ${ }^{1}$ Hal itu juga berlaku dalam dunia pendidikan, meskipun lembaga pendidikan tidak termasuk lembaga profit, namun pengelolaannya tidak dapat dilakukan secara tradisional akan tetapi membutuhkan kemampuan khusus sehingga output pendidikan memiliki daya saing tinggi untuk dapat bersaing di tingkat global.

Apabila saat ini paradigma dalam memandang pendidikan mulai bergeser, yang awalnya pendidikan dilihat dan dikaji dari aspek sosial, sekarang orang melihat pendidikan lebih pada sebuah corporate. Yaitu memandang pendidikan sebagai suatu organisasi produksi yang menghasilkan pemasaran pendidikan yang dapat di akses dengan mudah oleh konsumen. Apabila produsen tidak mampu memasarkan hasil produksinya, maka produksi yang ditawarkan tidak laku.

Strategi ini diadopsi dari dunia bisnis, dimana istilah marketing terfokus pada sisi kepuasan konsumen dengan dapat dilihat dari strategi yang berbasis media sosial dengan memakai dasar pemikiran yang logis. Dengan kata lain, jika lembaga pendidikan yang memproses pemasaran pendidikan tidak mampu menyesuaikan dengan zaman sekarang, maka lembaga pendidikan tersebut tidak akan berlaku untuk terus eksis. ${ }^{2}$ Lembaga pendidikan Islam merupakan satu kesatuan sosial masyarakat dalam bentuk miniatur. Sehingga terjadi sosialisasi dan kominikasi di dalamnya. Komunikasi merupakan bentuk hubungan manusia satu dengan lainnya. ${ }^{3}$

Maka lembaga pendidikan di sini dapat dimaknai sebagai sebuah lembaga yang bergerak di bidang layanan jasa pendidikan. Jadi jika lembaga ingin memberikan citra yang baik dalam rangka menarik jumlah siswa, maka konsekuensi logisnya lembaga pendidikan harus mengembangkan berbagai upaya manajemen strategi pemasaran sehingga customer tertarik untuk masuk lembaga pedidikan tersebut.

Konsep bisnis dan pemasaran sudah saatnya diterapkan dalam lembaga pendidikan sehingga dapat berkembang dan menyesuaikan dengan zaman dan menambah keutungan bagi lembaga pendidikan berbanding lurus dengan peminat lembaga pendidikan tersebut. Semakin bagus dalam mengelola pemasaran yang

\footnotetext{
${ }^{1}$ Muhaimin, Manajemen Pendidikan (Aplikasi dalam Penyusunan Rencana Pengembangan Sekolah/Madrasah), cet. Ke-4 (Jakarta: Kencana Prenada Media Group, 2012)

${ }^{2}$ Sri Minarti, Manajemen Sekolah (Mengelola Lembaga Pendidikan Secara Mandiri, (Yogyakarta: ArRuzz Media, 2011), 370-371.

${ }^{3}$ Hilmi Qosim Mubah, "PSIKOMANAJERIAL PERSONALIA PENDIDIKAN; MENGKONSTRUKSI PRODUKTIFITAS KERJA PERSPREKTIF IDENTIFIKASI KEMATANGAN PERSONAL." $A L$ FIKRAH: Jurnal Studi Ilmu Pendidikan dan Keislaman 2, no. 2 (2019): 105.
} 
dipasarkan melalui basis media sosial maka semakin banyak pula peminat yang akan melihat pemasaran yang diberikan sekolah tersebut.

Di sini sudah jelas manajemen strategi yang ditawarkan dengan pemasaran pendidikan sudah sangat menguntukan. karena Pemasaran secara umum adalah suatu proses kegiatan secara menyeluruh dan secara terpadu dan terencana, yang dilakukan oleh sebuah institusi/organisasi dalam menciptakan kebutuhan yang diinginkan melalui penciptaan penawaran, pertukaran produk yang bernilai dengan pihak lain. ${ }^{4}$ Selain itu juga saat ini, dunia tengah memasuki era revolusi industri 4.0. atau revolusi industri dunia keempat dimana teknologi telah menjadi basis dalam kehidupan manusia. Segala hal menjadi tanpa batas dan tidak terbatas akibat perkembangan internet dan teknologi digital. Era ini telah mempengaruhi banyak aspek kehidupan baik di bidang ekonomi, politik, kebudayaan, seni, dan bahkan sampai ke dunia pendidikan.

Pemanfaatan media sosial sebagai alat pemasaran dalam dunia pendidikan pada era revolusi industri 4.0 ini menjadi pilihan yang sangat tepat karena semakin mudah diakses oleh berbagai kalangan. Media sosial merupakan teknologi baru yang membuat kita lebih efektif dan efisien dalam membangun hubungan dengan pelanggan serta memiliki peluang besar untuk mendapat keuntungan bagi pelaku pemasaran. Sosial media sekarang telah memiliki peran penting dalam manajemen strategi pemasaran bisnis bahkan sudah masuk di pemasaran pendidikan. Kini berbagi informasi kepada pengunjung atau follower bukan satu-satunya keuntungan menggunakan sosial media bagi sebuah bisnis, tetapi juga membuat proses pengenalan ini menjadi lebih mudah dibandingkan dengan sebelumnya. Dengan perangkat pendukung yang ada, kini anda bisa mengetahui dengan terperinci mengenai siapa saja konsumen anda, bahasa yang mereka gunakan, rentang usia, bahkan jenis kelamin dari sosial media. Informasi ini dapat membantu proses branding dan promosi kepada target konsumen yang tepat.

Pelaku pemasaran melihat bahwa pengguna internet menjadi sasaran utama untuk pemasaran, sehinggga pada era revolusi industri 4.0 media sosial menjadi gaya baru dalam pemasaran pendidikan. Berdasarkan hal tersebut saya tertarik untuk meneliti Manajemen Strategik Pemasaran Pendidikan Berbasis Media Sosial Di Madrasah Aliyah Yayasan Pondok Pesantren Babakan Jamanis Parigi Pangandaran.

\section{METODE PENELITIAN}

Metode penelitian ini menggunakan metode kualitatif, yaitu pendekatan yang ditunjukan untuk mendeskrifsikan dan menganalisa fenomena, peristiwa, aktivitas sosial, sikap kepercayaan, persepsi, pemikiran orang secara individual maupun kelompok. ${ }^{5}$

Dalam pandangan fenomenologis, peneliti berusaha memahami peristiwa atau kejadian-kejadian yang ada kaitannya dengan orang dalan situasi tertentu dan terjadi dalam kehidupan sehari-hari. ${ }^{6}$

Salah satu argumen yang dikedepankan oleh metode penelitian kualitatif adalah keunikan manusia atau gejala sosial yang tidak dapat di analisa dengan metode statistik. Metode penelitian kualitatif menekankan pada metode penelitian observasi dan dialog (wawancara mendalam) di lapangan dan datanya dianalisis dengan cara nonstatistik.

\footnotetext{
${ }^{4}$ Yoyon Bakhtiar Irianto dan Eka Prihatin, Pemasaran Pendidikan (Bandung : Alfabeta, 2017), 337.

${ }^{5}$ Nana Syaodih, Metode penelitian Pendidikan (Bandung: PT. Remaja Rosdakarya ), 5.

${ }^{6}$ Lexy J. Moleong, Metode Penelitian Kualitatif (Bandung : PT. Remaja Rosda Karya, 2004), 9.
} 
Pendekatan kualitatif menekankan pada pemahaman dari dalam (verstehen): penalaran; definisi suatu situasi tertentu (dalam konteks tertentu); dan lebih banyak meneliti hal-hal yang berhubungan dengan kehidupan sehari-hari. Pendekatan kualitatif lebih menekankan pada proses dibandingkan dengan hasil akhir. Oleh karena itu, urutan kegiatan dapat berubah tergantung pada kondisi dan banyaknya gejala yang ditemukan. Dengan demikian, dalam penelitian kualitatif, pencarian jawaban mengenai realitas sosial yang terjadi tidak cukup ditelusuri hanya sebatas penyebab terjadinya realitas, tetapi samapai pada makna di baliknya.

Pendekatan ini diharapkan mampu memberikan gambaran secara terperinci mengenai manajemen strategi pemasaran pendidikan berbasis media sosial di Madrasah Aliyah Yayasan Pondok Pesantren Babakan Jamanis. Informasi yang diperoleh dari penelitian ini berdasarkan sample informasi mengenai strategi pemasaran berbasis media sosial. Pengambilan sample bukan untuk mewakili populasi, tetapi untuk meningkatkan relevansi informasi terhadap judul yang diteliti agar akurat.

Agar hasil dari penelitian tersusun secara sistematis, perlu dilakukan langkahlangkah seperti menelaah seluruh data dari berbagai sumber wawancara, observasi, maupun dokumentasi. Selanjutnya mereduksi dan memilih data yang benar-benar penting untuk menyusun dan menyajikan data ke dalam bentuk uraian singkat maupun dalam bentuk teks.

\section{HASIL DAN PEMBAHASAN}

\section{Manajemen strategik pemasaran pendidikan berbasis media sosial di Madrasah} Aliyah Yayasan Pondok Pesantren Babakan Jamanis Parigi Pangandaran

Manajemen adalah mencapai tujuan organisasional dengan tepat melaksanakan tugas dan dengan baik menggunakan sumber-sumber melalui pelaksanaan fungsifungsi manajemen yang terdiri dari perencanaan, pengorganisasian, pengadaan sumberdaya, pengkomunikasian, pemimpinan, pemotivasian, dan pengendalian atau pengontrolan. Untuk itu Manajemen strategik bertugas mengendalikan proses yang panjang, mengangkat dan menempatkan orang-orang yang terkait dalam proses itu. Dengan demikian, manajemen strategik adalah manajemen tingkat makro yang berurusan dengan perencanaan strategik dan pengambilan keputusan strategik, sedangkan manajemen lainnya merupakan manajemen tingkat mikro, yaitu menangani hal-hal yang berhubungan dengan pelaksanaan. ${ }^{8}$

Madrasah Aliyah Yayasan Pondok Pesantren Babakan Jamanis sebagai lembaga pendidikan yang bergerak di bidang pemasaran pendidikan selalu berusaha memberikan pelayanan yang terbaik kepada siswa-siswinya dalam proses belajar mengajar di Madrasah Aliyah Yayasan Pondok Pesantren Babakan Jamanis sebelum melakukan strategi pemasaran dengan cara mengidentifikasi segmentasi pasar dan melihat persaingan pasar yang ada. Banyaknya sekolah baru yang muncul dengan kualitas dan melakukan berbagai strategi untuk tetap eksis di kalangan masyarakat. Salah satu strategi tersebut ialah dengan melakukan strategi pemasaran sekolah.

\footnotetext{
${ }^{7}$ Lexy J. Moleong, Metode Penelitian Kualitatif ( Bandung : PT Rosda Karya, 2011), 248.

${ }^{8}$ Robby Arini dan Achmad Muhlis. "MANAJEMEN STRATEGIK MUTU REKRUTMEN TENAGA KEPENDIDIKAN DI INSTITUT AGAMA ISLAM NEGERI MADURA." re-JIEM (Research Journal of Islamic Education Management) 3, no. 1 (2020): 34.
} 
Dalam melakukan pemasaran sekolah, Madrasah Aliyah Yayasan Pondok Pesantren Babakan Jamanis memperhatikan langkah-langkah pokok pemasaran sebagai berikut: yang pertama; Perencanaan pemasaran sekolah merupakan serangkaian kegiatan persiapan pemasaran berupa ide-ide strategi pemasaran dan dokumen-dokumen yang dibutuhkan untuk kegiatan pemasaran memalui media sosial. Rencana pemasaran berguna membantu kita dalam membangun, mengarahkan, dan mengorganisasikan usaha atau kegiatan pemasaran tersebut. Dengan adanya rencana pemasaran, kita akan ditungtut menganalisa situasi pasar dimana produk kita dipasarkan dan bagaimana situasi atau keadaan pasar. ${ }^{9}$

Berdasarkan data yang dihasilkan dari penelitian melalui wawancara diketahui bahwa tujuan dari implementasi manajemen pemasaran pendidikan adalah sebagai bentuk dakwah dan menginformasikan perkembangan sekolah kepada masyarakat.

Secara umum tujuan pemasaran sekolah adalah menginformasikan kepada masyarakat tentang keunggulan sekolah agar masyarakat tertarik dan berusaha untuk memilih sekolah Madrasah Aliyah Yayasan Pondok Pesantren Babakan Jamanis sebagai tempat pendidikan yang diinginkan. Jadi dapat disimpulkan bahwa dalam pemasaran hal yang paling utama dilakukan yaitu dengan menentukan target pasar kemudian dengan perencanaan sekolah, dimana dalam hal pemasaran sekolah ini dapat merencanakan hal-hal apa saja yang dapat menarik masyarakat banyak untuk menyekolahkan anaknya disekolah tersebut.

Perencanaan kegiatan pemasaran pendidikan di Madrasah Aliyah Yayasan Pondok Pesantren Babakan Jamanis belum ada aturan bakunya mengenai manajemen strategi pemasaran pendidikan berbasis media sosial ini dan baru berjalan sekitar 3 tahun terakhir.

Madrasah Aliyah YPP Babakan Jamanis mempunyai strategi dalam memasarkan pendidikan berbasis media sosial dengan ciri khas sekolahnya, media sosial yang di gunakan dalam pemasaran pendidikan di Madrasah Aliyah Yayasan Pondok Pesantren Babakan Jamanis terfokus pada 3 media sosial yang pertama facebook dengan akun Madrasah Aliyah Yayasan Pondok Pesantren Babakan Jamanis yang mengelola akun tersebut sebagian dari guru yang mempunyai basic di bidang IT, pemasaran menggunakan facebook terbagi menjadi dua bagian ada yang bersifat fanspage dan ada yang bersifat grup, dalam pemasaran biasanya menggunakan fanspage ada beberapa fanspage seperti elnidavoice-official, osismaJamanis, pramuka-maJamanis, dan lainnya untuk grupnya ada Jamanis online tetapi sifatnya umum. yang kedua instagram untuk di instagram yang mengelola akun tersebut siswa-siswi Jurnalis yang aktif dalam strategi pemasaran berbasis media sosial, Jurnalis tersebut merupakan salah satu ekstrakulikuler yang ada di Madrasah Aliyah Yayasan Pondok Pesantren Babakan Jamanis. Dan yang ketiga youtube yang mengelola akun tersebut Bapak. Yusuf yang mempunyai basic di bidang IT cyber multimedia Jamanis TV nama akun Youtube strategi tersebut diharapkan bisa menarik banyak siswa untuk bersekolah ke Madrasah Aliyah Yayasan Pondok Pesantren Babakan Jamanis.

\footnotetext{
${ }^{9}$ Daryanto, Sari Kuliah Manajemen Pemasaran, cet. 1 ( Bandung: PT Sarana Tutorial Nurani Sejahtera, 2011), 117.
} 
Kedua; Pelaksanaan atau implementasi merupakan tahap selanjutnya dalam kegiatan pemasaran. Pada tahap ini setiap perencanaan yang dipersiapkan akan di implementasikan pada kegiatan-kegiatan pemasaran.

Dari pemaparan di atas dapat disimpulkan bahwa proses implementasi pemasaran di Madrasah Aliyah Yayasan Pondok Pesantren Babakan Jamanis yaitu dengan strategi pemasaran melalui media sosial Facebook, Instagram, dan Youtube. Dengan cara identifikasi terlebih dulu di lingkungan masyarakat, yang kemudian menjadi strategi pemasaran pendidikan dengan menonjolkan differensiasi (keberbedaan positif) Madrasah Aliyah Yayasan Pondok Pesantren Babakan Jamanis dengan sekolah lain.

Manajemen strategi pemasaran pendidikan berbasis media sosial untuk mengoptimalkan publikasi dalam upaya mempromosikan/memasarkan sekolah dengan ciri khas yang ada di sekolah Madrasah Aliyah Yayasan Pondok Pesantren Babakan Jamanis ini, selain itu kita harus terus mengikuti zaman di mana sekarang sudah masuk pada era 4.0 juga manajemennya bisa lebih terstuktur secara baik untuk mengoptimalkan lembaga pendidikan lebih baik.

\section{Faktor Pendukung Manajemen strategik pemasaran pendidikan berbasis media sosial di Madrasah Aliyah Yayasan Pondok Pesantren Babakan Jamanis Parigi Pangandaran}

Dalam dunia pendidikan manajemen strategi sangat dibutuhkan. Mengatur strategi yang dibuat dan direncanakan agar tujuan organisasi lembaga pendidikan yang dimaksud baik sekolah/madrasah dan perguruan tinggi dapat tercapai. Manajemen strategi pada umumnya dilakukan pada jangka menengah dan jangka panjang. Artinya bagaimana suatu lembaga atau madrasah merencanakan pengembangan lembaganya pada periode menengah dan jangka/periode panjang. ${ }^{10}$

Dalam pelaksanaan strategi pemasaran pendidikan manajemen strategik pemasaran pendidikan berbasis media sosial di Madrasah Aliyah Yayasan Pondok Pesantren Babakan Jamanis Parigi Pangandaran, yang menjadi faktor pendukung yang menunjang dalam kegiatan tersebut diantaranya: pertama; sumber daya pengelola yang cukup memadai dengan adanya guru-guru yang mahir dalam menggunakan teknologi informasi dan komunikasi. Kepala Madrasah Aliyah Yayasan Pondok Pesantren Babakan Jamanis juga memaparkan bahwa Strategi pemasaran pendidikan di Madrasah Aliyah Yayasan Pondok Pesantren Babakan Jamanis melalui media sosial sangat populer di masyarakat pertama Facebook, Instagram dan Youtube.

Kedua; lokasi lembaga pendidikan Madrasah Aliyah Yayasan Pondok Pesantren Babakan Jamanis sangat strategis sehingga Jaringan internet cukup memadai sehingga hampir tidak pernah terkendala dengan masalah jaringan.

Ketiga; respon masyarakat yang sangat antusias juga menjadi faktor yang mendukung dalam strategi pemasaran pendidikan. Terlebih Madrasah Aliyah Yayasan Pondok Pesantren Babakan Jamanis memiliki konten-konten yang menarik

\footnotetext{
${ }^{10}$ Ali Nurhadi, "IMPLEMENTASI MANAJEMEN STRATEGI BERBASIS PEMBIASAAN DALAM MENUMBUHKAN KARAKTER RELIGIUS SISWA DI SMAN 1 GALIS PAMEKASAN." al-Afkar, Journal For Islamic Studies 3, no. 1, January (2020): 65-76.
} 
dalam mempublikasikan lembaga, diantaranya bidang seni nasyid el-nida voice yang biasa tampil di beberapa event bahkan pernah menjuarai perlombaan nasyid di tingkat nasional sebagai juara ke-2 di syiar anak negeri, di bidang agama tahfidz yang rutin di adakan setiap libur sekolah.

\section{Faktor penghambat Manajemen strategik pemasaran pendidikan berbasis media sosial di Madrasah Aliyah Yayasan Pondok Pesantren Babakan Jamanis Parigi Pangandaran}

Selain dari faktor pendukung yang telah dijelaskan, terdapat faktor penghambat dalam melaksanakan strategi pemasaran pendidikan di MA Babakan Jamanis Pangandaran diantaranya: pertama; fasilitas fisik yang kurang lengkap menjadi faktor penghambat yang utama, menjadikan manajemen strategi pemasara pendidikan di Madrasah Aliyah Yayasan Pondok Pesantren Babakan Jamanis kurang maksimal dalam pelaksanaannya. Kedua; masih banyak masyarakat yang belum memiliki dan tidak menguasai alat komunikasi berupa handphone, sehingga informasi mengenai kelembagaan Madrasah Aliyah Yayasan Pondok Pesantren Babakan Jamanis minim terinformasikan kepada masyarakat. Oleh karena itu untuk masyarakat pelosok masih harus menggunakan media spanduk dalam menginformasikan lembaga kepada masyarakat.

Ketiga faktor penghambat yang lainnya yaitu peralatan yang kurang memadai yang bisa digunakan secara khusus untuk kegiatan pemasaran pendidikan. Dengan kata lain masih menggunakan fasilitas milik pribadi guru, sehingga ada keterbatasan dalam pelaksanaan maupun penggunaannya.

\section{KESIMPULAN}

Dari hasil penelitian tersebut, dapat disimpulkan bahwa Strategi pemasaran yang dilakukan Madrasah Aliyah Yayasan Pondok Pesantren Babakan Jamanis sudah mengikuti langkah-langkah strategi pemasaran dengan baik, mulai dari identifikasi masyarakat atau orang tua siswa sebagai objek manajemen strategi pemasaran pendidikan berbasis media sosial, menentukan tujuan dari pemasaran yang dilakukan sekolah.

Strategi pemasaran di Madrasah Aliyah Yayasan Pondok Pesantren Babakan Jamanis biasanya menggunakan strategi pemasaran klasik menggunakan brosur, pamflet dan dari informasi lisan. Dari pemasaran tersebut merupakan salah satu strategi yang dilakukan 3 tahun ke terakhir. sebelum strategi pemasaran pendidikan berbasis media sosial dilakukan di Madrasah Aliyah Yayasan Pondok Pesantren Babakan Jamanis.

Adapun media paling efektif yang digunakan dalam pemasaran di Madrasah Aliyah Yayasan Pondok Pesantren Babakan Jamanis adalah dengan manajemen strategi pemasaran pendidikan berbasis media sosial. Media sosial yang di gunakan dalam pemasaran pendidikan ada 3 yaitu facebook, instagram dan Youtube, Hal ini dikarenakan pemasaran melalui media sosial dianggap lebih efektif dan efesien menjangkau banyak kalangan.

Dengan strategi pemasaran pendidikan berbasis media sosial yang 3 tahun terakhir dilakukan oleh Madrasah Aliyah Yayasan Pondok Pesantren Babakan Jamanis ini dapat meningkatkan minat calon siswa untuk sekolah di Madrasah Aliyah Yayasan Pondok Pesantren Babakan Jamanis. Karena semakin mudah akses yang dapat dilihat melalui 
media sosial sebagai penunjang proses manajemen strategi pemasaran pendidikan yang diterima oleh kalangan masyarakat, orangtua siswa, bahkan calon siswa sebagai objek startegi pemasaran.

Dalam pelaksanaan manajemen starategi pemasaran tentunya akan nada faktor pendukung dan faktor penghambat diantaranya: faktor pendukung : a. sumber daya manusia sebagai pengelolanya ada b. jaringan internet cukup memadai c. peran konsumen dalam strategi pemasaran juga sangat berpengaruh. Faktor penghambat : a. waktu untuk proses pemasaran belum terstuktur b. fasilitas fisik kurang lengkap c. peralatan kurang lengkap.

\section{DAFTAR PUSTAKA}

Adita. Arus Metamorposa milenial. Yogyakarta: Emest, 2018.

Alma, Buchari. Manajemen Pemasaran dan Pemasaran Jasa, Bandung: Alfabeta, 2009.

Alma, Buchori dan Ratih Hurriyati. Manajemen Corporate dan Strategi Pemasaran Jasa Pendidikan Fokus pada Mutu dan Layanan Prima, Bandung: Alfabeta, 2007.

Arini, Robby, and Achmad Muhlis. "MANAJEMEN STRATEGIK MUTU REKRUTMEN TENAGA KEPENDIDIKAN DI INSTITUT AGAMA ISLAM NEGERI MADURA." re-JIEM (Research Journal of Islamic Education Management) 3, no. 1 (2020): 29-41.

Daryanto. Sari Kuliah Manajemen Pemasaran, cet. 1. Bandung: PT Sarana tutorial nurani sejahtera, 2011.

Harsanto, Budi. Inovasi Pembelajaran di Era Digital Menggunakan Geogle Sites dan Media Sosial. Bandung: Unpad Press, 2014.

Hasibuan, S.P. Malayu. Dasar-dasar Perbankan, Jakarta: Bumi Aksara, 2004.

Hasibuan, S.P. Malayu. Manajemen Dasar, Pengertian dan Masalah, Jakarta: Bumi Aksara, 2005

Hidayat, Ara dan Imam Machali. Pengelolaan Pendidikan; "Konsep, Prinsip dan Aplikasi dalam Mengelola Sekolah dan Madrasah”, Bandung: Pustaka Educa, 2010.

Irianto, Yoyon Bakhtiar dan Eka Prihatin. Pemasaran Pendidikan. Bandung : Alfabeta, 2017.

Lupiyuadi, Rambat. Manajemen pemasaran jasa berbasis kompetensi. Jakarta: Salemba Empat, 2013.

Miliza, Ghazali. Buat Duit Dengan Facebook dan Instagram (Panduan Menjama Pendapatan dengan Facebook dan Instagram), Malaysia: Publishing House, 2016.

Minarti, Sri. 2011 Manajemen Sekolah (Mengelola Lembaga Pendidikan Secara Mandiri), Yogyakarta: Ar-Ruzz Media.

Moleong, Lexy J. Metode Penelitian Kualitatif. Bandung : PT Rosda Karya, 2011.

Mubah, Hilmi Qosim. "PSIKOMANAJERIAL PERSONALIA PENDIDIKAN; MENGKONSTRUKSI PRODUKTIFITAS KERJA PERSPREKTIF IDENTIFIKASI KEMATANGAN PERSONAL." AL-FIKRAH: Jurnal Studi Ilmu Pendidikan dan Keislaman 2, no. 2 (2019): 99-118.

Muhaimin. Manajemen Pendidikan; Aplikasi Dalam Penyusunan Rencana Pengembangan Sekolah/Madrasah-Cetakan Ke-4. Jakarta: Kencana Prenada Media Group, 2012. 
Mulyasa, Enco. Manajemen Berbasis Sekolah; Konsep, Strategi, dan Implementasi, Jakarta: Remaja Rosdakarya, 2002.

Nurhadi, Ali "IMPLEMENTASI MANAJEMEN STRATEGI BERBASIS PEMBIASAAN DALAM MENUMBUHKAN KARAKTER RELIGIUS SISWA DI SMAN 1 GALIS PAMEKASAN." al-Afkar, Journal For Islamic Studies 3, no. 1, January (2020): 65-76.

Salbino, Sherief. Buku Pintar Gadget Android Untuk Pemula, Jakarta: Kunci Komunikasi, 2014.

Sedjati, Retina Sri. Manajemen strategi. Yogyakarta: Deepublish, 2012.

Sule, Ernie Trisnawati. Pengantar Manajemen, Jakarta: Kencana, 2005.

Syaodih, Nana. Metode Penelitian Pendidikan. Bandung: PT.Remaja Rosdakarya, 2013. Umiarso dan Imam Gojali. Manajemen Mutu Sekolah di Era Otonomi Pendidikan, "Menjual Mutu Pendidikan dengan Pendekatan Quality Control bagi Pelaku Lembaga Pendidikan”, Yogyakarta: IRCiSoD, 2010. 